\title{
COMPARISON BETWEEN OSSEOINTEGRATION OF TWO TYPES OF DELAYED PLACEMENT SELF DRILLING IMPLANTS IN MAXILLARY ANTERIOR REGION (CLINICAL TRIAL)
}

\author{
Mohammad S. Abd Elmaksoud ${ }^{1 *} B D S$,Magued H. Fahmy² $P h D$, \\ Marwa G. Noureldin ${ }^{3} P h D$.
}

\begin{abstract}
INTRODUCTION: Dental implants have become a treatment option widely used for replacement of lost teeth. Primary stability following implant placement is essential for ossseointegration and it is mainly affected by density and quantity of bone at the implant site.

OBJECTIVES: The aim of this study was to evaluate and compare the osseointegration between two types of dental implants with modified design features as regard to primary stability and bone density surrounding the self-drilling implants (Zinedent Tec-2 implant system) and the self-drilling compressive type implants (Roott -implant system) after delayed placement of the implants in upper anterior region.

METHODS: A randomized prospective clinical and radiographic trial conducted on ten patients were included in the study. The patients were indicated for dental implant placement in the upper anterior region. The patients were randomly allocated into two groups equally by simple random technique. The Presurgical phase was done by assessment of the patients clinically and radiographically. The surgical phase for both groups included implant placement then measuring the primary stability of the implants using the periotest device. The follow-up phase comprised clinical evaluation of gingival condition, implant mobility. Radiographical evaluation was performed by measuring the bone density using digital periapical $\mathrm{X}$-ray, densitometer block and Image $\mathrm{J}$ software. In the prosthetic phase, a porcelain fused to metal restoration was delivered.

RESULTS: After comparing the results of primary stability and the bone density surrounding the implants of both groups, it was shown that the average of mean, median and standard deviation for group B (Roott -implant system) were greater than group A (Zinedent Tec-2 implant system) but the differences were statistically insignificant.

CONCLUSION: The self-drilling implants is a new modality for easier manipulation of implant insertion and less postoperative complications with good outcomes.

KEY WORDS: Osseointegration. Self-drilling, Compressive implants, Delayed placement.

RUNNING TITLE: Evaluation of Self Drilling Dental Implants.
\end{abstract}

1BDS,2008, Faculty of Dentistry, Alexandria University, Egypt.

2Professor of Oral and Maxillofacial Surgery, Department of Oral and Maxillofacial Surgery Faculty of Dentistry, Alexandria University, Egypt.

3Lecturer of Oral and Maxillofacial Surgery, Department of Oral and Maxillofacial Surgery Faculty of Dentistry, Alexandria University, Egypt.

* Corresponding Author:

E-mail: dr.mohammadsalah10@gmail.com

\section{INTRODUCTION}

Dental implants have become a treatment option widely used for replacement of lost teeth to restore natural contour, function, comfort, aesthetics, speech and health. The success of implant therapy depends on appropriate treatment planning and properly performed implant placement surgery $(1,2)$.

A decade ago, the waiting time required as a healing period before implant placement procedure for missing tooth varied from 6 to 12 month $(3,4)$.

Dental implants can be placed in fresh sockets just after tooth extraction (5), but late implantation after complete osseous healing of the dental socket is the most likely procedure (6).

There are two types of the implants design; macro design and micro design. The former includes threads geometry and body shape while the latter consists of implant material and surface treatment and morphology (7).

Problems associated with placing endosseous implants are implant fixation, heat generation during drilling, inflammation of the surrounding soft tissue, fibrous connective tissue in the receptor sites, space around the implant, and inadequate soft tissue for primary closure (8-10).

The self-drilling implants had sharp threads to make osteotomy with very minimal preparation in the alveolar bone to preserve it, so the direct bone cut around the implant facilitate bone growth and increase the osseointegration to the implant surface, progression of bone healing determine the success of the dental implants (11-18).

The aim of this study was to evaluate and compare the osseointegration between two types of dental implants with modified design features as regard to primary stability and bone density surrounding the self-drilling implants (Zinedent Tec-2 implant system) and the self-drilling compressive type implants (Roott -implant system) after delayed placement of the implants in upper anterior region. 


\section{PATIENTS AND METHODS}

Study design: This study is a randomized prospective clinical and radiographic study; the study was conducted on ten patients requiring implants in maxillary anterior region.

Study sample: Ten patients were selected from outpatient clinic of the Oral Surgery Department, Faculty of Dentistry, Alexandria University. All were randomly allocated into two groups according to Kim and Shin (19).

Sample size estimation: A minimal total sample size of sixteen dental implants in ten patients (divided into two groups eight implants for each group) was needed to detect an average significant difference between the 2 types of delayed placement self-drilling dental implants for the implant stability quotients and osseointegration (among the two groups) at $90 \%$ power and 95 confidence level using a Mann Whitney-U Test (20).

All procedures were done in accordance with Ethic research committee, Faculty of Dentistry, Alexandria University.

\section{Eligibility Criteria's}

Inclusion criteria:

- Patients were free of any relevant systemic diseases.

- Patients age ranged from 20 to 50 years of both sexes.

- Patients were psychologically accepting the implant placement at the maxillary anterior region and the involved procedure.

- $\quad$ The interocclusal space at implant site was not less than 8 $\mathrm{mm}$.

- Patients who were motivated, cooperative and with good oral hygiene according to O'Leary Index (21).

Exclusion criteria:

- Presence of infection clinically or by radiograph.

- Patient with parafunctional habits.

- Patients receiving chemotherapy.

- Heavy smokers.

- Pregnant women.

All patients were informed about the aim of this study and an informed consent was obtained from all patients after explaining all the procedures including all the benefits and side effects in a simple and easy way.

Standardization for the following was made to increase the accuracy of the results:

- The implant size used was (3.5 diameters and 10mm length) for all patients

- Postoperatively, the digital periapical x-ray with $0.88 \mathrm{kv}$ was used with cone paralleling technique (XCP holding system) and densitometer block for all patients.

- Sidexis 4 and image $\mathrm{J}$ software to analyze the data from $\mathrm{x}$ rays were used for all patients (22).

Densitometer: A simple lightweight device was constructed using barium sulfate as the major radiopaque component. The $5 * 32 * 12 \mathrm{~mm} 3$ resin block has eight segments with known densities ranging from $1.304(\mathrm{~g} / \mathrm{cm} 3)$ to $1.982(\mathrm{~g} / \mathrm{cm} 3)$. The device was integrated into an XCP unit for standard intraoral radiographs and placed between the jaws for computer aided tomographic imaging. The relationship between the device segment densities and the optical densities of the exposed film was plotted $(23,24)$.

For group A: Zinedent implants (Tech-2 implants, Zinedent Implant manufacturing Inc., Paragon Plaza, Ankara, Turkey, Lot\#1302345) are manufactured utilizing a medical grade titanium alloy Grade 23(Ti-6Al-4V ELI) and come in 3 diameters and 5 lengths $(\varnothing \quad 3.5, \varnothing 04.3, \varnothing \quad 5.0$ and $8 \mathrm{~mm}, 10 \mathrm{~mm}, 12 \mathrm{~mm}, 14 \mathrm{~mm}, 16 \mathrm{~mm})$.

Product features:

- Surface roughened by SLA technology.

- Conical implant body design with Morse taper connection.

- Double helical thread design.

- Cervical diameter equal to implant body diameter.

- Single prosthetic connection for all implant diameters.

- Milling speed (revolution per minute): 500 to $800 \mathrm{rpm}$.

- Placement speed (revolution per minute): $30 \mathrm{rpm}$, Maximum insertion torque: 60 N.cm.

The apical $5 \mathrm{~mm}$ of the implant is machine finished to maintain sharp cutting edges, while the surface is created using an abrasive particle jet concept with controlled grain oxides of the implant surface. All implants are sterilized by gamma radiation.

For group B: Roott dental implant system (Roott implants, TARTE AG Inc., seestrasse 588806 Bach SZ, Switzerland, Lot\#35102). The compressive implant is a one-piece implant with compression threads. It is used for single or multiple unit restorations with immediate loading in upper and lower jaw with adequate bone tissue and can be used with flap and flapless technique. Implants available in 4 diameters and 5 lengths (ø 3.5, ø 4, ø 4.5, ø 5 and 8mm, 10mm, 12mm, 14mm, $16 \mathrm{~mm})$

\section{Product features:}

- Abutment direction can be adjusted using special instrument up to 15 degree relative to the implant axis.

- High precision cone.

- Adjustable abutment slope angle.

- Bone condensation design.

- Compact size with round indicator and high precision cone provides more accurate esthetic construction.

- Special compression threads

- Radial micro threads space

- The threads are left machine finished to retain its sharp cutting edges with aggressive threads. The implant creates its own osteotomy by shaving the surrounding bone as its being placed for perfect fit without any pressure or gaps.

Implant primary stability analysis device (Periotest ${ }^{\mathrm{TM}}$ )

It is a device which is electrically driven and the electronically monitored with a tapping head that percusses the implant for a total of 16 times. The entire measuring procedure takes 4 seconds. The instrument includes a tapping rod that impacts the implant assembly. The readings are from -8 to +50 (25). (Periotest device, DENTI Inc., H-1112 Budapest Tippan u.2.A, Hungary.)

All patients went through preoperative phase including clinical examination of recipient site to ensure absence of infection or any signs of inflammation, radiographic examination of recipient site to be implanted by CBCT. (Figure 1)

Surgical phase began using of chlorohexidine mouth wash for thirty seconds before operation. Infiltration anesthesia using Mepecaine hydrochloride 2\% (Alexandria pharmaceutical company, Alexandria, Egypt). Surgical exposure of the maxillary crest by paracrestal incision and buccal reflection was performed. (Figure 2A) Drilling was carried out through the maxilla according to manufacturer's instructions. (Figure 
2B) The implants were screwed directly into the osteotomy site, primarily the screwing was done mechanically by Fixture Mount Connection attached to the implant carrier. (Figure 2C) Suturing of the wound using 3-0 black silk was then performed followed by measuring the implant primary stability using Periotest $^{\mathrm{TM}}$ (buccopalatal, mesiodistal and apical directions) (25). (Figure 3)

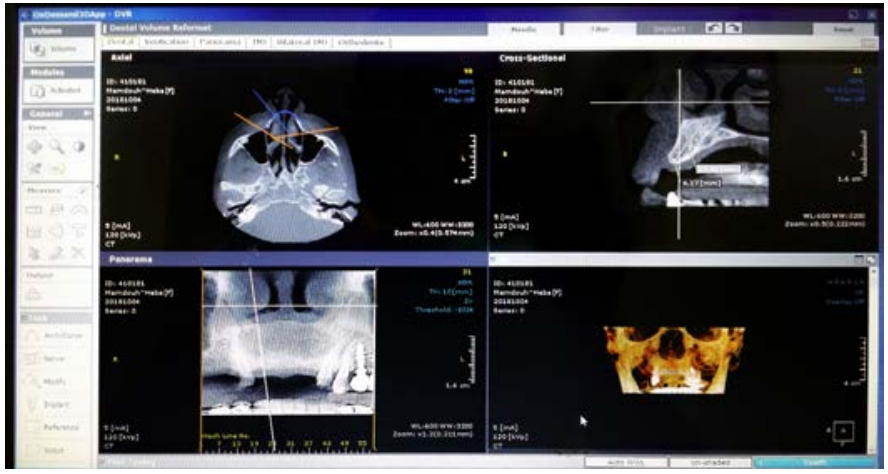

Figure 1: Preopertive CBCT

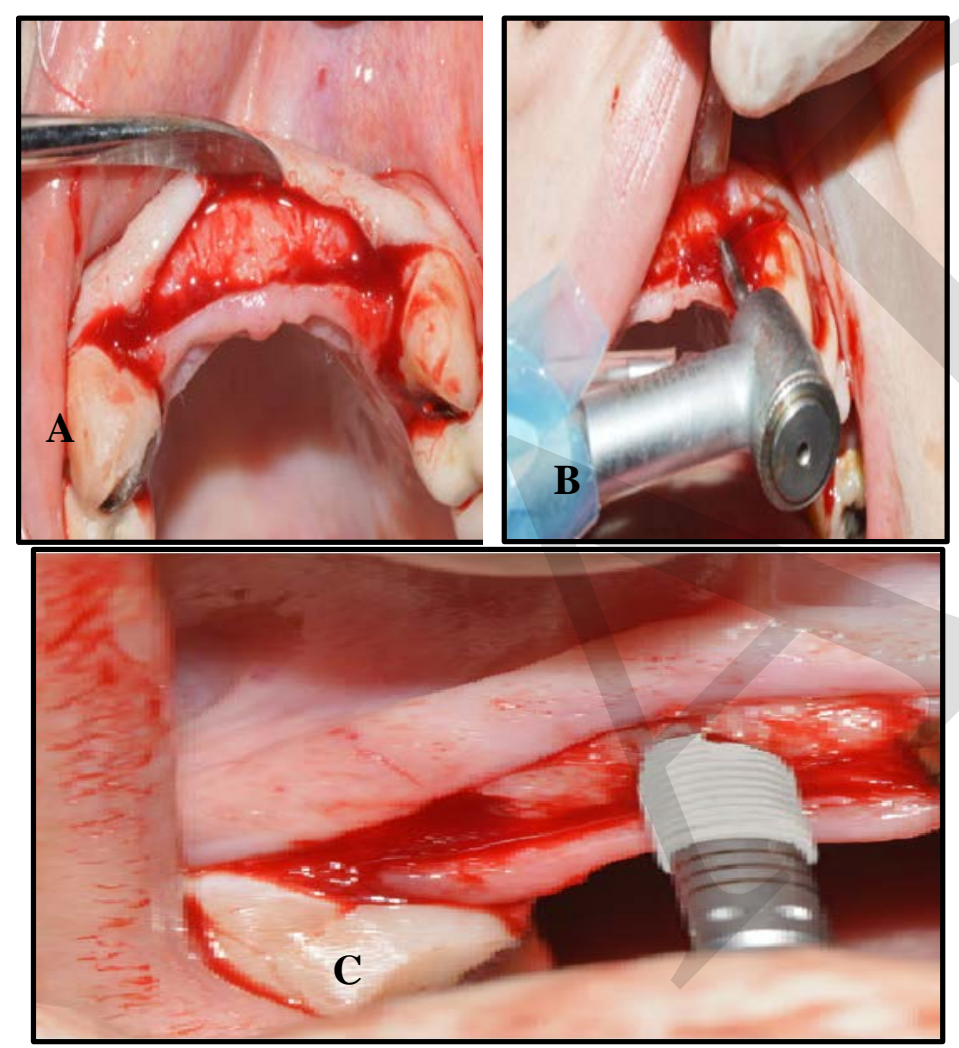

Figure 2 : (A) Paracrestal inscion with buccal reflection. (B)

Drilling of the osteotomy site. (C) Placement of implant into osteotomy site.

Postoperative instructions included: cold packs on the first day, then warm mouth wash for the following days and oral hygiene instructions.

Postoperative medications included antibiotic: Amoxicillin $500 \mathrm{mg}$ and 125mg clavulanic acid (Augmentin ${ }^{\circledR}$ 625mg, Galaxosmithkline co ltd, Stockley Park West, Uxbridge,United Kingdom) 1 capsule every 8 hours for 6 days postoperatively and non-steroidal anti-inflammatory drugs:
Diclofenac potassium 50mg tablets (Cataflam ${ }^{\circledR} 50 \mathrm{mg}$, Novartis Pharmaceuticals Corporation, Basel, Switzerland)1 tablet 3 times daily after meals for 4 days.

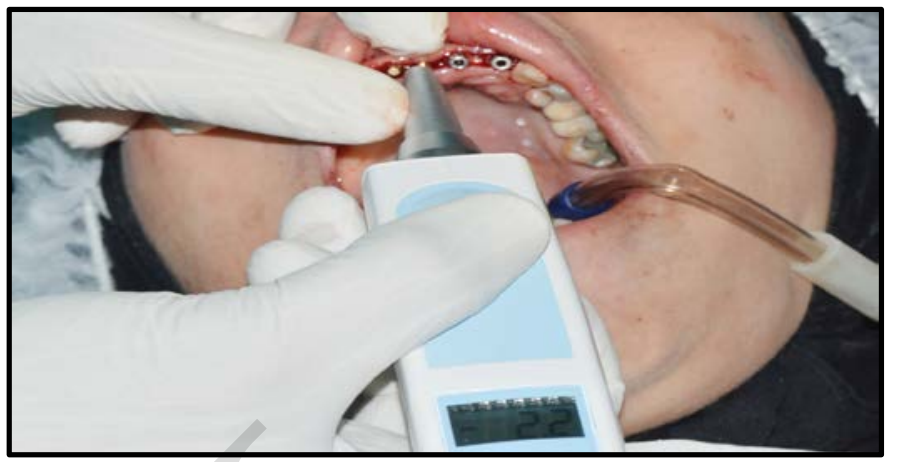

Figure 3: Measuring primary stability using Periotest TM device.

The sutures were removed after one week postoperatively followed by immediate placement of nonfunctional provisional superstructure for both groups.

Postoperative Regular follow-up for all patients was done at the first week, then at one month, three months, and at six months interval post operatively check for:

1. Gingival condition was assessed for pain, tenderness, bleeding on probing (BOP) and peri-implants probing depth according to Gallagher and Silver (26).

- Pain: was evaluated postoperatively using the visual analogue scale (VAS) on the first and seventh days. Patients were asked about the pain severity according to the VAS scale.

- Postoperative edema: Edema was evaluated by its ability to pit (27). The examiner fingers are pressed into dependent area of the patient skin for 5 seconds. The finger was sinking into the tissue and leaves an impression when they are removed. The pitting is graded on a scale of +1to+4 as follows: +1 (trace) slight indentation rapid return to normal, +2 (mild) the indentation returns to normal in few seconds, +3 (moderate) $6 \mathrm{~mm}$ indentation rebounds in 10-20 Seconds, +4 (sever) $8 \mathrm{~mm}$ indentation rebounds after $>30$ seconds.

- Bleeding on probing (BOP): BOP has been used to assess peri-implant tissue conditions around implants. BOP (notated in clinical records as $\mathrm{BOP}+$ ) elicited after the insertion of a probe into the sulcus with light pressure has been shown to detect the presence of an inflammatory lesion in the gingiva around teeth with a normal and a healthy but reduced periodontium. On the other hand, absence of bleeding on probing (BOP-) has been reported to represent periodontal health with a negative predictive value of $98.5 \%$ (28).

- Probing depth was assessed according to Gallagher and Silver Probing pocket depth refers to the distance from the gingival margin to the bottom of the pocket. Mesial and distal pockets were measured from the buccal aspect as close as possible to contact points while facial and lingual pockets were measured at the midline of the implant. Depth of the peri-implant sulcus was made with light force to avoid undue tissue damage and over extension into the healthy tissue (26). 
2. Implant mobility was assessed according to Mickinney et al $(29,30)$.It was tested using back and forth pressure by two instrument handles. Implant mobility indicates lack of osseointegration. Therefore, mobility was used as a specific diagnostic test pointing to loss of osseointegration and being decisive in making the decision to remove the affected implant. The clinical implant mobility scale is: Scale 0: Absence of clinical mobility in any direction. Scale 1: Slight detectable horizontal movement. Scale 2 : Moderate visible horizontal mobility up to $0.5 \mathrm{~mm}$. Scale 3: Severe horizontal movement greater than $0.5 \mathrm{~mm}$. Scale 4: Visible moderate to severe horizontal movement and any visible vertical movement.

3. Radiographic Evaluation Immediate, 3 and 6 months postoperative were assessed using digital periapical $\mathrm{x}$-ray films with X.C.P, densitometer block and Image J software (Image J Software, Image processing \& analysis, 1.31V) done for evaluating the changes in bone density surround the implants (Figure 4) (29).

Prosthetic phase: Final porcelain fused to metal restoration delivered after six months postoperatively (Figure 5).

\section{Statistical Analysis of the data}

Data was fed to the computer and analyzed using International Business Machines Statistical Package for the Social Sciences (IBM SPSS) software package version 20.0.(Armonl, NY: IBM Corp). Qualitative data were described using number and percent. Quantitative data were described using range (minimum and maximum), mean, median and standard deviation.

The used tests were:

1- Mann Whitney test.

2- Student t-test.

3- Paired t-test.
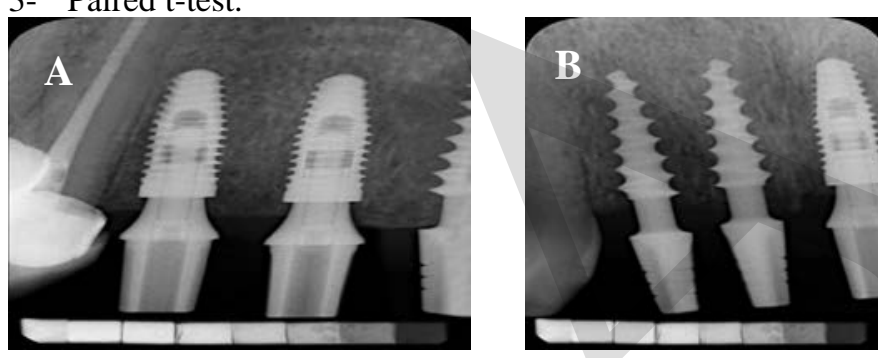

Figure 4: Periapical radiograph was made with the densometer in place (A and B).

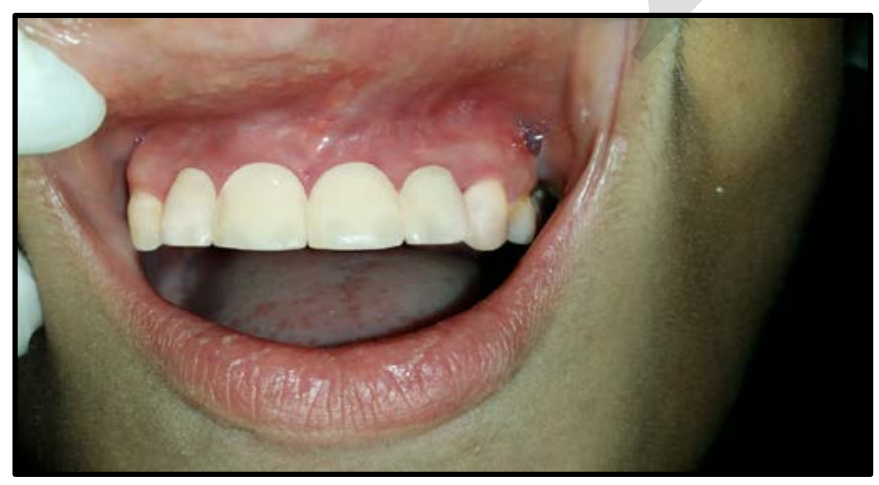

Figure 5: Placement of abutment and final prosthesis.

\section{RESULTS}

A total of sixteen self-drilling implants were placed in the maxillary anterior region, eight implants were placed using Ziendent Tec-2 implant system and eight implants were placed using Roott implant system placed in ten patients (7 females and 3 males with age range of 20 to 50 years). Patients were divided into two groups 5 patients in each; group A received Ziendent Tec-2 implant system and the group B received Roott implant system). All patients were suffering from missing maxillary anterior teeth. All patients had undergone surgical procedures for delayed implant placement and loading.

In the surgical phase the primary stability for both groups were measured by using the periotest device. After comparing the results of primary stability of two studied groups it was shown that the average of mean, median and standard deviation of primary stability of all cases of group B who received Roott implant system was $-3.53,-3.3$ and 0.7882 indicating greater primary stability than all cases of group A in which the average of mean, median and standard deviation of primary stability was $-2.83,-2.83$ and 0.5981 and the p-value of the study was 0.458 which is statistically insignificant.(Table 1)

After surgery, the ten patients' experience to pain at the surgical site was; one patient had slight pain (the score 1-3) and showed mild edema which subsided totally by the 2nd post-operative day. Seven patients had moderate pain (the score 4-6) and showed mild edema which subsided totally by the 3rd post-operative day. Two patients had severe pain (the score 7-9) and showed moderate edema which subsided totally by the 4th post-operative day.

Table 1:Comparison between the two studied groups according to average of primary stability.

\begin{tabular}{|l|l|l|l|l|}
\hline & $\begin{array}{l}\text { Group } \\
\text { A }\end{array}$ & $\begin{array}{l}\text { Group } \\
\text { B }\end{array}$ & t & p \\
\hline Mean & -2.83 & -3.53 & \multirow{2}{*}{0.792} & 0.458 \\
\cline { 1 - 3 } Median & -2.83 & -3.3 & & \\
\cline { 1 - 3 } $\begin{array}{l}\text { Standard } \\
\text { deviation }\end{array}$ & 0.5981 & 0.7882 & & \\
\hline
\end{tabular}

Bleeding on probing (BOP): All the patients had negative bleeding on probing (BOP-) throughout the follow up periods. Peri-implant probing depth: On the third month, the mean probing depth scores for the group A was $1.80 \pm 0.26$ with a minimum recorded value of 1.50 and a maximum recorded value of 2.25, while the mean probing depth scores for the group $\mathrm{B}$ was $1.73 \pm 0.25$ with a minimum recorded value of 1.50 and a maximum recorded value of 2.0. This difference in the probing depth score between the both groups was not found to be statistically significant. $(p=0.517)$. On the sixth month, the mean probing depth scores for the group A was $1.25 \pm 0.41$ with a minimum recorded value of 0.75 and a maximum recorded value of 2 , while the mean probing depth scores for the group B was $1.20 \pm 0.33$ with a minimum recorded value of 0.75 and a maximum recorded value of 1.50. This difference in the probing depth score between the both groups was not found to be statistically significant. $(\mathrm{p}=0.766)$. 
Implant mobility: throughout the evaluation period, none of the implants showed any signs of mobility. (i.e. mobility score was 0)

The radiographic evaluation for bone density surrounding the implants according the time of post-operative $x$ - ray:

1- Immediate: After comparing the results of the bone densities of the two studied groups it was shown that the average mean, median and standard deviation of all cases of group B who received Roott implant system were 1.934(g/cm3), $1.934(\mathrm{~g} / \mathrm{cm} 3)$ and 0.0378 which was greater than the average mean, median and standard deviation of all cases of group A who received Zinedent implant system which were $1.890(\mathrm{~g} / \mathrm{cm} 3), 1.890(\mathrm{~g} / \mathrm{cm} 3)$ and 0.0296 with a pvalue of 0.365 which was statistically insignificant.

2- After three months: After comparing the results of the bone densities of the two studied groups it was shown that the average mean, median and standard deviation of all cases of group B who received Roott implant system was $1.882(\mathrm{~g} / \mathrm{cm} 3), 1.882(\mathrm{~g} / \mathrm{cm} 3)$ and 0.0378 which is greater than the average mean, median and standard deviation of all cases of group A who received Zinedent implant system which was 1.861(g/cm3), 1.861(g/cm3) and 0.0296 with a p- value of 0.390 which was statistically insignificant.

3- After six months: After comparing the results of the bone densities of the two studied groups it was shown that the average mean, median and standard deviation of all cases of group B who received Roott implant system was $1.936(\mathrm{~g} / \mathrm{cm} 3), 1.936(\mathrm{~g} / \mathrm{cm} 3)$ and 0.0378 which were greater than the average mean, median and standard deviation of all cases of group A who received Zinedent implant system which were $1.882(\mathrm{~g} / \mathrm{cm} 3), 1.882(\mathrm{~g} / \mathrm{cm} 3)$ and 0.0296 with a pvalue of 0.251 which is statistically insignificant. (Table 2)

Assessment of bone density around the implants through the different periods in the same group:

For group A: Immediately post-operative, the maximum average of bone density was $1.936(\mathrm{~g} / \mathrm{cm} 3)$ and the minimum average of bone density was $1.861(\mathrm{~g} / \mathrm{cm} 3)$. The mean, median and standard deviation values calculated for of all cases of group A was $1.890(\mathrm{~g} / \mathrm{cm} 3), 1.890(\mathrm{~g} / \mathrm{cm} 3)$ and 0.0296 . After three months post-operative, the maximum average of bone density was $1.882(\mathrm{~g} / \mathrm{cm} 3)$ and the minimum average of bone density was $1.734(\mathrm{~g} / \mathrm{cm} 3)$. The mean, median and standard deviation values calculated for of all cases of group A was 1.861 $(\mathrm{g} / \mathrm{cm} 3), 1.861(\mathrm{~g} / \mathrm{cm} 3)$ and 0.0296 . After six months post-operative, the maximum average of bone density was $1.936(\mathrm{~g} / \mathrm{cm} 3)$ and the minimum average of bone density was $1.861(\mathrm{~g} / \mathrm{cm} 3)$. The mean, median and standard deviation values calculated for of all cases of group A was 1.882(g/cm3), 1.882(g/cm3) and 0.0296 .

For group B: Immediately post-operative, the maximum average of bone density was $1.982(\mathrm{~g} / \mathrm{cm} 3)$ and the minimum average of bone density was $1.882(\mathrm{~g} / \mathrm{cm} 3)$. The mean, median and standard deviation values calculated for of all cases of group A was $1.934(\mathrm{~g} / \mathrm{cm} 3), 1.934(\mathrm{~g} / \mathrm{cm} 3)$ and 0.0378 . After three months post-operative, the maximum average of bone density was $1.936(\mathrm{~g} / \mathrm{cm} 3)$ and the minimum average of bone density was $1.861(\mathrm{~g} / \mathrm{cm} 3)$. The mean, median and standard deviation values calculated for of all cases of group A was 1.882(g/cm3), $1.882(\mathrm{~g} / \mathrm{cm} 3)$ and 0.0378 . After six months post-operative, the maximum average of bone density was $1.982(\mathrm{~g} / \mathrm{cm} 3)$ and the minimum average of bone density was
1.882 (g/cm3). The mean, median and standard deviation values calculated for of all cases of group A was 1.936(g/cm3), 1.936(g/cm3) and 0.0378 .

Table 2: Comparing the results of the bone densities of the two studied groups after six months.

\begin{tabular}{||l|l|l|l|c||}
\hline & $\begin{array}{l}\text { Group } \\
\text { A }\end{array}$ & Group B & t & p \\
\hline Mean & 1.882 & 1.936 & \multirow{2}{*}{0.365} & 0.251 \\
\cline { 1 - 3 } Median & 1.882 & 1.936 & & \\
\hline $\begin{array}{l}\text { Standard } \\
\text { deviation }\end{array}$ & 0.0296 & 0.0378 & & \\
\hline
\end{tabular}

\section{DISCUSSION}

The aim of this study was to evaluate and compare the osseointegration between two types of dental implants with modified design features as regard to primary stability and bone density surrounding the self-drilling implants (Zinedent Tec-2 implant system) and the self-drilling compressive type implants (Roott -implant system) after delayed placement of the implants in upper anterior region.

In this study a total of sixteen self-drilling implants were placed in the maxillary anterior region, eight implants were placed using Ziendent Tec-2 implant system and eight implants were placed using Roott implant system. Ten patients who were suffering from missing maxillary anterior teeth ( 7 females and 3 males with age range of 20 to 50 years) were divided into two groups with 5 patients in each. Group A received Ziendent Tec-2 implant system and group B received Roott implant system.

All implants in this study where placed in the prepared site by free hand technique. This is supported by a study conducted by Brignardello-Petersen R (31) in (2017), Park C et al (32) in (2009) where they recommended that this technique didn't have an effect on failure or success the dental implants and this technique depends on the operator skills.

In this study, eight patients needed single implants (unilateral), which was simple along with short operating time and favorable outcomes. While, two other patients needed four implants (bilateral), which was time consuming and caused slight discomfort for the patients during the operation. This coincided with the systematic review of Schneider et al (33) in 2016.

In this study to increase the accuracy of the results the standardization done for the following: The implant with size (3.5 diameters and 10mm length) were placed in all patients. Postoperatively the digital periapical $\mathrm{x}$-ray with $0.88 \mathrm{kv}$ and used with cone paralleling technique (XCP holding system). Sidexis 4 and image $\mathrm{J}$ software were used to analyze the data from $\mathrm{x}$ rays for all patients (22), Densitometer blocks were placed for all patients (23).

In our study, eight patients experienced slight to mild pain at the surgical site which disappeared completely after the 2nd and 3rd postoperative days, and mild edema with two patients which completely disappeared after 4 days. This is in comparison to studies done by Clark WA et al. (2016) (34) where drilling into healed sites result in more heat generation and more postoperative pain and edema, because more amount of bone is being prepared. 
Regarding the mean peri-implant probing depth in the present study there was no significant increase throughout the evaluation period, which indicates successful implants, that was considered to be an important criterion for implant success in accordance with Pour et al., 2018 (35).

Regarding the gingival condition around the implants, all cases showed a sulcus bleeding index score of 0 and negative bleeding on probing (BOP -) throughout the evaluation period indicating absence of infection or peri-implant mucositis, which is a criteria of implant success. The peri-implant mucositis may lead to progressive bone destruction (periimplantitis) and ultimately to implant failure as reported by Esposito et al (2015) (36). Also, stating that the extension of peri-implant mucositis can spread to the bone leading to periimplantitis and implant failure.

Regarding implant mobility, no clinical mobility was detected in any of the implants throughout the follow up period. This was confirmed by radiographic evaluation that revealed intimate bone implant contact and absence of peri-implant radiolucency. This indicates proper osseointegration of all implants. The absence of implant mobility is considered to be important criteria for implant success in accordance with Chrcanovic

et al (2017) (37).

Regarding to evaluation of osseointegration for both groups in this study, the mean of the primary stability values for each implants of group A and group B was recorded immediately post-operative assessed by periotest machine was $(-2.83)$ for group A and (-3.35) for group B. The difference in primary stability values for each group was found to be statistically insignificant ( $p$-value $>0.05$ ). The results were found to be satisfying and that was in agreement with Jeong MA et al who mentioned that the primary stability of implants with degrees from -8 to 0 were considered to be a good indication for future implant osseointegration and the implant can be loaded (38).

The mean of bone density values was recorded immediate, after three months and after six months post-operatively. The high peri-implant bone density values immediately after placement of implants was related to the accumulation of bone particles around apex of the implant. In group A, it was due to the apical $5 \mathrm{~mm}$ of the implant which is machine finished to maintain sharp cutting edges to facilitate bone condensation around it. For group B, the special compression threads of the implant which is left machine finished to retain sharp cutting edges with aggressive threads, the implant creates its own osteotomy by shaving the surrounding bone as its being placed for perfect fit without any pressure or gaps creating a layer of compacted bone around the implant. That was in agreement with Jeong MA et al. (38)

The decrease of values of the bone density for each group after three months post-operatively was related to the remodeling processes of the bone around the implant surfaces That was in agreement with Hong DG (2017). (39)

Then the increase of values of the bone density for each group after six months post-operatively indicates osseointegration of all implants. That was in agreement with Bosshardt DD et al. (2017). (40)

Regarding to comparison the osseointegration between group $\mathrm{A}$ and group $\mathrm{B}$, the mean bone density values were recorded immediate, after three months and after six months postoperatively. Regarding the bone density values immediately,

Alexandria Dental Journal. Volume 46 Issue 2 Section A after three and after six months post-operatively. The difference in bone density values for both groups were found to be statistically insignificant ( $p$-value $>0.05$ ) at all intervals. That was in agreement with Chappuis V et al. (2017) (40)

\section{CONCLUSIONS}

From the results of this study it was concluded that: delayed implant placement is a successful treatment option for replacement of extracted tooth. The self-drilling implants is a new modality for easier manipulation of implant insertion and less postoperative complications with good outcomes.

\section{CONFLICT OF INTEREST}

The authors declare that they have no conflicts of interest.

\section{REFERENCES}

1- Zhang YX, Wu YH, Yao DS, Yang JY, Gao L. An experimental study of the effect of extraction and retention of canine primary intruded teeth to the permanent successors. Zhonghua Kou Qiang Yi Xue Za Zhi. 2018;53:344-50.

2- Chappuis V, Araújo MG, Buser D. Clinical relevance of dimensional bone and soft tissue alterations post-extraction in esthetic sites. Periodontol. 2017;73:73-83.

3- Sadek MM, Sabet NE, Hassan IT. Alveolar bone mapping in subjects with different vertical facial dimensions. Eur J Orthod. 2015;37:194-201.

4- Tallgren A. The continuing reduction of the residual alveolar ridges in complete denture wearers: A mixed longitudinal study covering 25 years. J Prosthet Dent. 2003;27:120-32.

5- Griggs JA. Dental Implants. Dent Clin North Am. 2017;61:857-71.

6- Chidagam PRLV, Gande VC, Yadlapalli S, Venkata RY, Kondaka S, Chedalawada S. Immediate versus delayed loading of implant for replacement of missing mandibular first molar: A randomized prospective six years clinical study. J Clin Diagn Res. 2017;11:ZC35-ZC9.

7- Al-Johany SS, Al Amri MD, Alsaeed S, Alalola B. Dental implant length and diameter: A proposed classification scheme. J Prosthodont. 2017;26:252-60.

8- Hammerle CH, Araújo MG, Simion M. Evidence-based knowledge on the biology and treatment of extraction sockets. Clin Oral Implants Res. 2012;23:80-2.

9- Karl M, Irastorza-Landa A. Does implant design affect primary stability in extraction sites? Quintessence Int. 2017;48:219-24.

10-Doi K, Kubo T, Kajihara S, Makihara Y, Oue H, Oki Y, et al. A stability evaluation of a novel titanium dental implant/interconnected porous hydroxyapatite complex under functional loading conditions. Dent Mater J. 2017;36:647-53.

11-Mangano FG, Mastrangelo P, Luongo F, Blay A, Tunchel S. Aesthetic outcome of immediately restored single implants placed in extraction sockets and healed sites of the anterior maxilla: a retrospective study on 103 patients with 3 years of follow-up. Clin Oral Implants Res. 2017;28:272-82.

12-Bonnet F, Karouni M, Antoun H. Esthetic evaluation of periimplant soft tissue of immediate single-implant 
placement and provisionalization in the anterior maxilla. Int J Esthet Dent. 2018;13:378-92.

13-Schropp L, Kostopoulos L, Wenzel A. Bone healing following immediate versus delayed placement of titanium implants into extraction sockets: a prospective clinical study. Int J Oral Maxillofac Implants. 2003;18:189-99.

14-Adell R, Eriksson B, Lekholm U, Branemark PI, Jemt T. Long-term follow-up study of osseointegrated implants. Int J Oral Maxillofac Implants. 2005;5:347-60.

15-Toyoshima T, Wagner W, Klein MO, Stender E, Wieland M, Al-Nawas B. Primary stability of a hybrid self-tapping implant compared to a cylindrical non-self-tapping implant with respect to drilling protocols in an ex vivo model. Clin Implant Dent Relat Res. 2011;13:71-8.

16-Zadeh PT. Self osteotomizing bone implant and related methods of application. 2014 Available at: http://www.google.com.pg/patents/US20140329202.

17-Reynders RM, Cacciatore G. No confidence that success rates of self-drilling and self-tapping insertion techniques of orthodontic mini-implants are similar. Evid Based Dent. 2016;17:111-3.

18-Todorovic VS, Vasovic M, Beetge MM, van Zyl AW, Kokovic V. Stability development of immediately loaded hybrid self-tapping implants inserted in the posterior maxilla: 1-year results of a randomized controlled trial. J Oral Implantol. 2017;43:33-8.

19-Kim J, Shin W. How to do random allocation (randomization). Clin Orthop Surg. 2014;6:103-9.

20-Lioubavina-Hack N, Lang NP, Karring T. Significance of primary stability for osseointegration of dental implants. Clin Oral Implants Res. 2006;17:244-50.

21-O'Leary J, Drake B, Naylor E. The plaque control record. J Periodontol. 1972;43:39.

22-Olsson A, Oturai AB, Søndergaard HB, Sellebjerg F, Oturai PS. Bone microarchitecture and bone mineral density in multiple sclerosis. Acta Neurol Scand. 2018;137:363-9.

23-Yang J, Chiou R, Ruprecht A, Vicario J, MacPhail LA, Rams TE. A new device for measuring density of jaw bones. Dentomaxillofac Radiol. 2002;31:313-6.

24-Persson C, Guandalini L, Baruffaldi F, Pierotti L, Baleani M. Radiopacity of tantalum-loaded acrylic bone cement. Proc Inst Mech Eng H. 2006;220:787-91.

25- Andreotti AM, Goiato MC, Nobrega AS, Freitas da Silva EV, Filho HG, Pellizzer EP, et al. Relationship between implant stability measurements obtained by two different devices: A systematic review. J Periodontol. 2017;88:281-8.

26-Bijur PE, Silver W, Gallagher EJ. Reliability of the visual analog scale for measurement of acute pain. Acad Emerg Med. 2001;8:1153-7.

27-Brodovicz KG, McNaughton K, Uemura N, Meininger G, Girman CJ, Yale SH. Reliability and feasibility of methods to quantitatively assess peripheral edema. Clin Med Res. 2009;7:21-31.

28-Newbrun E. Indices to measure gingival bleeding. J Periodontol. 1996;67:555-61.

29-Malo P, de Araujo Nobre M, Lopes A. The use of computer-guided flapless implant surgery and four implants placed in immediate function to support a fixed denture: preliminary results after a mean follow-up period of thirteen months. J Prosthet Dent. 2007;97:S26-34.

Alexandria Dental Journal. Volume 46 Issue 2 Section A
30-Steflik DE, Koth DL, Robinson FG, McKinney RV, Davis $\mathrm{BC}$, Morris CF, et al. Prospective investigation of the single-crystal sapphire endosteal dental implant in humans: ten-year results. J Oral Implantol. 1995;21:8-18.

31-Brignardello-Petersen R. Single anterior maxillary dental implants have good esthetic and patient satisfaction outcomes 3 years after placement. J Am Dent Assoc. 2017;148:e27.

32-Park C, Raigrodski AJ, Rosen J, Spiekerman C, London RM. Accuracy of implant placement using precision surgical guides with varying occlusogingival heights: an in vitro study. J Prosthet Dent. 2009;101:372-81.

33-Schneider U, Moser L, Fornasetti M, Piattella M, Siciliani G. Esthetic evaluation of implants vs canine substitution in patients with congenitally missing maxillary lateral incisors: Are there any new insights? Am J Orthod Dentofacial Orthop. 2016;150:416-24.

34-Clark WA, Garber DA, Salama MA, Goldstein RE. The Implant Practice. Dent Today. 2016;35:84,86,88.

35-Pour NN, Ghaedi B, Sohrabi M. Soft-tissue esthetic outcome of single implants: Immediate placement in fresh extraction sockets versus conventional placement in healed sockets. J Indian Soc Periodontol. 2018;22:249-53.

36-Esposito M, Maghaireh H, Pistilli R, Grusovin MG, Lee ST, Gualini F, et al. Dental implants with internal versus external connections: 1-year post-loading results from a pragmatic multicenter randomised controlled trial. Eur J Oral Implantol. 2015;8:331-44.

37-Chrcanovic BR, Kisch J, Albrektsson T, Wennerberg A. Impact of Different Surgeons on Dental Implant Failure. Int J Prosthodont. 2017;30:445-54.

38-Jeong MA, Jung MK, Kim SG, Oh JS. Implant stability measurements in the long-term follow-up of dentis implants: A retrospective study with periotest. Implant Dent. 2015;24:263-6.

39-Hong DGK, Oh JH. Recent advances in dental implants. Maxillofac Plast Reconstr Surg. 2017;39:33.

40-Bosshardt DD, Chappuis V, Buser D. Osseointegration of titanium, titanium alloy and zirconia dental implants: current knowledge and open questions. Periodontol 2000. 2017;73:22-40. 